\title{
OP QPel: (Microbiology \\ ROLE OF SOCIO-DEMOGRAPHY AND BLOOD PARAMETERS IN SUSCEPTIBILITY TO PULMONARY TUBERCULOSIS
}

\section{Debosmita Paul*}

\section{Wasifa Parween}

Model Rural Health Research Unit, Department Of Health Research, Indian Council Of Medical Research, Agartala, India. *Corresponding Author

Regional Medical Research Centre, Indian Council Of Medical Research, Dibrugarh, India.

ABSTRACT) Tuberculosis (TB) disease can progress in a multitude of directions subject to various intrinsic and extrinsic factors on host immune system, starting from genetic insult to nutritional and physiological state of the host. This study was conducted to assess the major socio-demographic characteristics and hematological and biochemical abnormalities for their role in susceptibility to pulmonary tuberculosis. 94 study subjects were enrolled in this study, of which 34 subjects comprised of new case Active Pulmonary TB (PTB), 30 with latent tuberculosis (LTB) and 30 healthy household subjects. All related demographic, socio-economic along with clinical data were collected through a predesigned and pre-tested questionnaire. (2-3) $\mathrm{ml}$ blood was drawn from each study subject aseptically for routine blood examination using automated cell counter. The male: female ratio for $\mathrm{PTB}=2.1: 1, \mathrm{LTB}=1.3: 1$, household contacts $=0.7: 1$. Mostly Hindus $(97.05 \%$ PTB, $90 \%$ LTB, $93.33 \%$ healthy) with higher proportion of married subjects among all groups $(73.53 \%$ PTB cases, $70 \% \mathrm{LTB}, 63.33 \%$ healthy) observed. $65 \%$ of PTB patients were illiterate or educated up to primary level with $40 \%$ of both LTB and household contacts with secondary education. $11.76 \%$ of PTB patients and $33.33 \%$ with LTB had family history of the disease. Prevalence of TB was higher among the poorer strata with $76.47 \%$ and $70 \%$ respectively in those with PTB and LTB. Male gender, marriage, positive family history and basiceducation/illiteracy were found to be associated with disease susceptibility. Anemia and leukocytosis were observed among PTB patients as compared to those with LTB and household contacts.

KEYWORDS : Socio-demography; Hematology, Pulmonary Tuberculosis, Latent Tuberculosis, Hemoglobin, Leukocytes

\section{INTRODUCTION}

Tuberculosis (TB) is a chronic infectious disease that affects millions of Indians and a major public health problem worldwide which is caused by a single infectious agent, Mycobacterium tuberculosis. TB has caused the highest number of deaths ranking above HIV/AIDS. ${ }^{3}$ Tuberculosis is most prevalent in underdeveloped countries due to unsanitary living conditions, crowded living quarters and marginalized group of people. ${ }^{5}$ In India, around 2.8 million cases whereas, in Assam a total of 40,174 cases of TB have been detected in 2018. ${ }^{4}$ The common symptoms of active pulmonary tuberculosis are coughing, sometimes with sputum or blood, chest pain, weakness, weight loss, fever and night sweats. ${ }^{6}$ The disease can progress in a multitude of directions subject to the influence of various intrinsic and extrinsic factors on host immune system, starting from genetic insult to the immune make-up to nutritional and physiological state of the host. ${ }^{7}$ TB spreads from an infected person to a healthy person through air droplets generated by cough, sneeze or saliva. It is suggestive of the fact that if a person is left untreated, each person with active TB disease will infect on an average between 10 to 15 persons every year and this continues the transmission of the disease. ${ }^{8}$ In some studies it has been found that the hematological as well as biochemical abnormalities are common in active pulmonary TB cases. ${ }^{9}$

This study has been done with the objective of assessing the major socio-demographic characteristics and the hematological and biochemical abnormalities for their role in susceptibility to pulmonary tuberculosis and also to use as an aid for the diagnosis of the disease.

\section{METHODOLOGY}

\section{Study Design}

This case control study was carried out from July'2016 to June'2017 in the Department of Microbiology \& Multidisciplinary Research Laboratory, Assam Medical College \& Hospital in Dibrugarh, Assam. The samples were collected from the Department of Tuberculosis and Respiratory Diseases, Integrated Counselling and Testing Centre of the Department of Microbiology. All clinically suspected newly diagnosed sputum smear positive TB cases both male/female over 15 years of age were included in this study. Subjects with HIV infection and immunosuppressive diseases were excluded. All related demographic, socio-economic, and clinical and morbidity data were collected through a predesigned and pre-tested proforma after proper informed consent was obtained in writing. The study was approved by the Institutional Ethics Committee (Human), Assam Medical College \& Hospital, Dibrugarh.

\section{Sample collection and Laboratory methods}

A total of 94 study subjects were enrolled in this study, out of which 34 subjects comprised of new case with Active Pulmonary Tuberculosis (PTB) or smear positive pulmonary tuberculosis. 30 subjects with Mantoux and IGRA (Interferon gamma release assay) test positive but asymptomatic for TB were included in the latent infection group. Also, 30 healthy household subjects from among the family members and close asymptomatic contacts of pulmonary tuberculosis patients who tested negative for $M$. tuberculosis infection were enrolled in this study. The Latent tuberculosis patients $(\mathrm{n}=30)$ and household contacts $(\mathrm{n}=30)$ were accordingly recruited in $1: 1$ proportion. About $2-3 \mathrm{ml}$ of blood was drawn from each study subjects aseptically by venipuncture and kept in EDTA vials for routine examination of blood (R/E blood) using automated cell counter (Ac-T5diffCPfromBeckmanCoulter, USA).

\section{Statistical Analysis}

Statistical analysis was done using the Microsoft Excel, 2007, Epi Info 7 software and online software like Social Science Statistics and Graph Pad Version 7.0.1. Non parametric tests were done as and when necessary. Tests were considered to be significant if $\mathrm{p}$ value was $<0.05$.

\section{RESULT}

Baseline characteristics of the three study groups, i.e. active TB, latent infection and household contacts regarding age were same. Preponderance of tuberculosis among males was higher in the study population. The male: female ratio for Active TB (PTB) is 23:11, Latent TB (LTB) 17:13 and household contacts is 13:17. The study subjects were mostly Hindus $(97.06 \%$ active TB, $90 \%$ latent TB, $93.33 \%$ in healthy) and the proportion of married subjects was higher among all groups with $73.53 \%$ of active TB cases, $70 \%$ of latent TB and $63.33 \%$ of healthy controls married. $65 \%$ of active TB patients were illiterate or educated up to primary level whereas $40 \%$ both latent tubercular and household contacts have received secondary education. Only $11.76 \%$ of active TB patients and $11 \%$ of patients with latent TB had family history of Tuberculosis and all of the study subjects in household contact group were exposed to the disease. Incidence of both pulmonary tuberculosis and latent infection was found to be higher in the lower socioeconomic strata with $76.47 \%$ and $70 \%$ respectively in both the groups. The socio-demographic data are as given in table-1. Active TB patients were found to have lower hemoglobin at an average $(9.1 \pm 2.56) \mathrm{g} / \mathrm{dl}$., followed by latent TB subjects with average hemoglobin of $(11.13 \pm 2.23) \mathrm{g} / \mathrm{dl}$. as compared to household contacts with $(12.94 \pm 1.96) \mathrm{g} / \mathrm{dl}$., which were statistically significant $(\mathrm{p}<0.05)$. Total leucocyte count (TLC) was significantly higher in active TB patients $(9111 \mathrm{~g} / \mathrm{dl}$.) followed by latent TB patients $(8860 \mathrm{~g} / \mathrm{dl}$.) compared to the household healthy control group $(6503 \mathrm{~g} / \mathrm{dl}$.). The mean hemoglobin level and total leucocyte count 
(TLC) in the active tubercular, latent infection and household contact group are as given in Table 2 .

\section{DISCUSSION}

In the present study, 94 adult participants of both sexes were included. Study subjects were divided into three groups- one group of case, including 34 active pulmonary TB cases (males and females) and two control groups (latent TB and household healthy contacts) with 30 individuals, age matched and of both sexes in each group. The study groups were comparable in baseline characteristics regarding age of the subjects. There was a male preponderance seen in the pulmonary tuberculosis patients with male: female ratio being 23:11 in the smear positive group. In a study by Oliver Neyrolles it was found that $70 \%$ of those who develop tubercular disease are male. ${ }^{10}$ Conversely, the human population is remarkably resistant to $M$. tuberculosis, but women are hypothesized to be even more resistant to the bacillus than men. ${ }^{10}$ Sex-specific features of nutrition and metabolism maybe associated with susceptibility or resistance to Mycobacterium tuberculosis. For instance, iron is a critical component of several enzymes and redox systems in mycobacteria, as in all living organisms and fat metabolism also influences infections. Many studies have established clear links between sex-specific factors, including steroid hormones and genetic variants and the differential susceptibility of males and females to a number of other infectious and non-infectious diseases. ${ }^{11}$ Social factors, lifestyle habits such as smoking ${ }^{12}$, higher participation in working group may define sex differences along with biological factors such as estrogen ${ }^{13}$ and cholesterol levels ${ }^{14}$, insulin sensitivity ${ }^{15}$ and obesity ${ }^{16}$. Furthermore, most of active TB (74\%) patients were married. Similar observation has also been made by Mohamed S et al who reported $82.6 \%$ of pulmonary tuberculosis patients to be married. ${ }^{17}$ Bhatt et al also inferred occurrence of TB inclined (55\%) towards married subjects as compared to the unmarried group. ${ }^{18}$ The reason for this may be negligence of one's own health owing to family responsibilities. However, study by Horwitz $\mathrm{O}$ in Denmark between 1960 and 1968 showed that married men had the lowest incidence of tuberculosis for all age groups and the rates were twice as high among single and widowed men, and four times higher among divorced men. ${ }^{19}$ Jethani $\mathrm{S}$ et al too reported minimum (36\%) sputum positivity amongst married. ${ }^{20}$ The reason cited is that singles may tend to seek early care subject to less burden of responsibilities compared to the married couples. Most (65\%) of active TB and latent
TB patients were found to be illiterate or educated upto primary level in this study. Jethani $\mathrm{S}$ et al did a study where they had similar type of observation where $58.8 \%$ of TB patients were illiterate or educated up to primary level. ${ }^{21}$ Shetty $\mathrm{N}$ et al found low level of education as a risk factor for TB. ${ }^{22}$ Chelleng PK et al found $40.1 \%$ illiterate in pulmonary TB patients in tea garden communities of Assam and reported being illiterate as a risk factor for $\mathrm{TB} .{ }^{23} \mathrm{This}$ can be ascribed to the fact that the tea-tribe were the majority in our study population and higher education is not very prevalent yet among the adults. However, the pattern is gradually improving. Family history of TB was found only in $11 \%$ of active TB patients and $30 \%$ of latent TB patients. Amongst 13 of the study subjects having family history of (h/o) TB, $4(30.76 \%)$ had active TB. In a study by Jethani S et al it was found that $5 \%$ of study subjects had family history of TB and among 18 subjects who had family history of TB, $50 \%$ were found to be sputum smear positive. ${ }^{21}$ Chelleng PK et al in their study found family history of TB among $43.5 \%$ of study subjects. ${ }^{23}$ This is an indication for including family history in the TB screening process for further refinement.

The level of hemoglobin in active tubercular patients was found to be significantly low as compared to latent infection. The hemoglobin level in household contacts is comparatively higher. Studies have shown that anemia is highly prevalent among adults with pulmonary tuberculosis. ${ }^{25}$ This is also in concordance with the findings of Sei Won Lee et al who stated that anemia is a common hematological abnormality in patients with TB and close observation is sufficient for tuberculosis associated anemia, because TB-associated anemia is usually mild and resolves with anti-TB treatment. ${ }^{24}$ In a study conducted in Ghana, $50 \%$ adults with pulmonary tuberculosis had significantly lower hemoglobin than healthy matched controls. Iron deficiency during the pathogenesis of tuberculosis may also be a precipitating factor. ${ }^{26}$ The total leucocyte count was found to be higher in active TB patients compared to latent TB and household healthy contacts which is in concordance with studies by Veenstra $\mathrm{H} \mathrm{et} \mathrm{al} .{ }^{27}$ and Wang $J$ et al. ${ }^{28}$ Nwanko et al. ${ }^{29}$ in a study from Nigeria reported significant leukocytosis (neutrophilia with toxic granulation) and Morris et al. found occurance of leukocytosis to be $40 \%$ in severe pulmonary tuberculosis patients. ${ }^{30}$ This is in agreement to the conventional conclusion resulting from increase in polymorphonuclear leukocytes and macrophages as the natural immune defense mechanism to combat invading pathogens.

Table 1: Demographic, Personal Parameters Of Subjects With Active Pulmonary Tuberculosis, Latent Tuberculosis And Household Contacts:

\begin{tabular}{|c|c|c|c|c|c|c|}
\hline \multirow[t]{2}{*}{ Variable } & \multirow{2}{*}{$\begin{array}{l}\text { Active TB } \\
(\mathrm{n}=36)\end{array}$} & \multirow{2}{*}{$\begin{array}{l}\text { Latent TB } \\
(\mathrm{n}=30)\end{array}$} & \multirow{2}{*}{$\begin{array}{l}\text { Household } \\
(\mathrm{n}=30)\end{array}$} & \multicolumn{3}{|c|}{ Chi Square p-value } \\
\hline & & & & Active TB vs Latent TB & Active TB vs. Household & Latent TB vs. Household \\
\hline Age in years (Mean $\pm S D$ & $33.35 \pm 12.3$ & $32.33 \pm 11.7$ & $33.83 \pm 10.7$ & & & \\
\hline \begin{tabular}{|ll} 
Sex & \\
$\cdot$ & Male \\
$\cdot$ & Female
\end{tabular} & \begin{tabular}{|l|}
$23(63.8)$ \\
$11(32.35)$
\end{tabular} & $\begin{array}{l}17(56.66) \\
13(43.33)\end{array}$ & $\begin{array}{l}13(43.33) \\
17(56.66)\end{array}$ & 0.36 & 0.05 & 0.3 \\
\hline $\begin{array}{ll}\text { Religion } \\
\text { - } & \text { Hindu } \\
\text { - } & \text { Islam } \\
\text { - } & \text { Christian } \\
\text { - } & \text { Others }\end{array}$ & $\begin{array}{l}33(97.05) \\
0 \\
1(27.77) \\
0\end{array}$ & $\begin{array}{l}27(90) \\
2(66.67) \\
1(33.33) \\
0\end{array}$ & $\begin{array}{l}28(93.33) \\
1(33.33) \\
1(33.33) \\
0\end{array}$ & 0.88 & 0.9 & 0.84 \\
\hline $\begin{array}{ll}\text { Marital Status } \\
\text { - } & \text { Married } \\
\text { - } & \text { Unmarried } \\
\text { - } & \text { Widwer }\end{array}$ & $\begin{array}{l}25(73.53) \\
9(26.47) \\
0\end{array}$ & $\begin{array}{l}21(70) \\
9(30) \\
0\end{array}$ & $\begin{array}{l}19(63.33) \\
9(30) \\
2(6.67)\end{array}$ & 0.75 & 0.62 & 0.86 \\
\hline 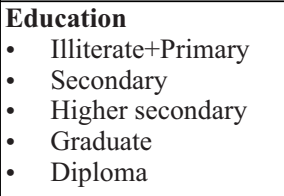 & $\begin{array}{l}22(64.7) \\
8(23.52) \\
3(8.82) \\
1(2.94) \\
0\end{array}$ & $\begin{array}{l}9(30) \\
12(40) \\
2(6.67) \\
1(3.33) \\
6(20)\end{array}$ & $\begin{array}{l}10(33.33) \\
12(40) \\
3(10) \\
2(6.67) \\
3(10)\end{array}$ & 0.18 & 0.18 & 0.81 \\
\hline $\begin{array}{l}\text { Family H/O TB } \\
-\quad \text { Yes } \\
\text { - } \quad \text { No }\end{array}$ & $\begin{array}{l}4(11.76) \\
30(88.23)\end{array}$ & $\begin{array}{l}10(33.33) \\
20(66.67)\end{array}$ & & 0.037 & & \\
\hline $\begin{array}{ll}\text { Socioeconomic status: } \\
\text { - } & \text { High } \\
\text { - } & \text { Middle } \\
\text { - } & \text { Low }\end{array}$ & $\begin{array}{l}0 \\
8(23.53 \%) \\
26(76.47 \%)\end{array}$ & $\mid \begin{array}{l}0 \\
9(30 \%) \\
21(70 \%)\end{array}$ & $\left|\begin{array}{l}0 \\
17(56.7 \%) \\
13(43.33 \%)\end{array}\right|$ & 0.016 & & \\
\hline
\end{tabular}


Volume - 10 | Issue - 12 | December - 2020 | PRINT ISSN No. 2249 - 555X | DOI : 10.36106/ijar

Table 2: General Laboratory Parameters Of Subjects With Active Pulmonary Tuberculosis, Latent Tuberculosis And Household Contacts:

\begin{tabular}{|l|l|l|l|l|l|}
\hline Variable & $\begin{array}{l}\text { Active TB } \\
(\mathbf{n}=\mathbf{3 4})\end{array}$ & $\begin{array}{l}\text { Latent TB } \\
(\mathbf{n}=\mathbf{3 0})\end{array}$ & $\begin{array}{l}\text { Household } \\
(\mathbf{n}=\mathbf{3 0})\end{array}$ & Reference Range & p value \\
\hline $\begin{array}{l}\text { Hemoglobin (gm/dl) } \\
\text { Mean } \pm \text { S.D. }\end{array}$ & $9.1 \pm 2.56$ & $11.13 \pm 2.23$ & $12.94 \pm 1.96$ & $(13-18) \mathrm{g} / \mathrm{dl}$. & 0.001 \\
\hline $\begin{array}{l}\text { Total Leucocyte Count } \\
\text { Mean } \pm \text { S.D.) }\end{array}$ & $9111 \pm \mathbf{0}$ & $8860 \pm \mathbf{0}$ & $6503 \pm \mathbf{0}$ & $4000-11000$ & 0.001 \\
\hline
\end{tabular}

\section{Table 2: p-values were calculated by ANOVA}

\section{REFERENCES}

1. https://www.sentinelassam.com/breaking-news/some-thoughts-on-defeating-tb-inassam/

2. Van TH, Velavan TP, Thye T, Meyer CG. Human genetic factors in tuberculosis: an update. Trop. Med. Int. Health, 22 (9) (2017), pp. 1063-1071.

3. World Health Organization. World Health Organization (ed.) Appia, Geneva, Switzerland: WHO Press; 2016. Global tuberculosis report.http://www.who. int/tb/publications/global_report/en.[Google Scholar]

4. India TB Report. Revised National TB control programme. Annual status report. Central TB division. Ministry of Health and Family Welfare, New Delhi. 2018. http://www.tbcindia.gov.in.

5. Valin N, Antoun F, Chouaid C, et al. Outbreak of tuberculosis in a migrants' shelter, Paris,France.2002.IntJTubercLungDis.2005;9(5):528-533. https://www.researchgate. Paris,France.2002.IntJTubercLungDis.2005;9(5):528-533. https://Www.researchgate.
net/publication/7864844_Outbreak_of_tuberculosis_in_a_migrants'_shelter_Paris_Fr ance 2002

6. Herzog H, Basil M. History of tuberculosis. Respiration 1998;65:7-9.

7. Paul D, Saikia L, Parween W. Polymorphism in the NRAMP1 gene as a risk factor for pulmonary tuberculosis -A case control study.IndianJMicrobiolRes.2019;6(3):266271.

8. Ministry of Health and Family Welfare. Estimated Global Incidence. RNTCP status report 2011.TB India 2011, New Delhi: Central TB Division, 2011.

9. Morris, CW, Bird AR, Nell H. 1989. The haematological and biochemical changes in serere 10. Neyrolles O, Quintana-Murci L (2009) Sexual Inequality in Tuberculosis. PLoS Med

11. Alagas ME, Mourtzoukou EG, Vardakas KZ. 2007. Sex differences in the incidence and severity of respiratory tract infections. Respir Med 101:1845-1863.

12. Reichert VC, Seltzer V, Efferen LS, Kohn N. Women and tobaccodependence. Med Clin North Am 2004;88(6):1467-81.

13. Klein SL. The effects of hormones on sex differences in infection: from genes to behavior. NeurosciBiobehav Rev2000;24(6):627-38

14. Knopp RH, Paramsothy P, Retzlaff BM, Fish B, Walden C, Dowdy A, et al. Gender differences in lipoprotein metabolism anddietary response: basis in hormonal differences and implicationsfor cardiovascular disease. CurrAtheroscler Rep differences and implicationsfor cardiovascular disease. CurrAtheroscler Rep 2005;7(6):472-9.

15. Sarafidis PA, McFarlane SI, Bakris GL. Gender disparity inoutcomes of care and management for diabetes and themetabolic syndrome. CurrDiabetes Rep 2006;6(3):219-24.

16. Hu FB. Overweight and obesity in women: health risks andconsequences. J Womens Health (Larchmt) 2003;12(2):163-72.

17. Mohamed S, Kanagasabapathy S, Khalifulla S. Socio-economic profile and risk factors among pulmonary tuberculosis patients in Madurai, India: a cross-sectional study. Int J Res Med Sci 2015 Dec;3(12):3490-8.

18. Bhatt CP, Bhatt AB, Shrestha B. Tuberculosis patients opinion for directly observed treatment short -course chemotherapy (DOTS) program of Nepal. SAARC J Tuber Lung Dis HIV/AIDS;VI(1):39-45.

19. Horwitz O. Tuberculosis risk and marital Status. Am Rev Respir Dis [serial online] 1971 Jul;104(1):22-31. Available from: URL: http://www.atsjournals.org/doi/ abs/10.1164/arrd.1971.104.1.22

20. Jethani S, Kakkar R, Semwal J, Rawat J. Socio-demographic profile of tuberculosis patient: a hospital based study at Dehradun. Natl J Community Med [serial online] 2014 Jan-Mar;5(1):6-9. Available from: URL: http://www.njcmindia.org/ home/download $/ 509$.

21. Jethani S, Semwal J, Kakkar R, Rawat J. Study of epidemiological correlates of tuberculosis. Indian J Comm Health 2012 Oct-Dec;24 (4):304-9.

22. Shetty N, Shemko M, Vaz M, D'Souza G. An epidemiological evaluation of risk factors for tuberculosis in South India: a matched case control study. Int J Tuberc Lung Dis 2006 Jan;10(1):80-6.

23. Chelleng PK, Devi KR, Borbora D, Chetia M, Saikia A, Mahanta J, et al. Risk factors of pulmonary tuberculosis in tea garden communities of Assam, India. Indian J Med Res 2014 Jul;140(1):138-41.

24. Lee SW, et al. The Prevalence and Evolution of Anemia Associated with Tuberculosis, J Korean Med Sci 2006;21:1028-32

25. Karyadi E, Schultink W, Nelwan RH, Gross R, Amin Z, Dolmans WM, et al. Poor micronutrient status of active pulmonary tuberculosis in Indonesia. J Nutr. 2000;130:2953-8

26. Lawn SD, Obeng J, Acheampong JW, Griffin GE. Resolution of acute phase response in West African patients receiving treatment for pulmonary tuberculosis. Int J Tuberc Lung Dis. 2000;4:340-4.

27. Veenstra H, Baumann R, Carroll NM, Lukey PT, Kidd M, Beyers N et al. Changes in leucocyte and lymphocyte subsets during tuberculosis treatment: prominence of CD3 $\operatorname{dim}$ CD 56+ natural killer T cells in fast treatment responders. Clin Exp Immunol 2006 Aug;145(2):252-60.

28. Wang J, Yin Y, Wang X, Pei H, Kuai S, Gu L, et al Ratio of monocytes to lymphocytes in peripheral blood in patients diagnosed with active tuberculosis. Braz J Infect Dis [serial peripheral blood in patients diagnosed with active tuberculosis. Braz J Infect Dis [serial
online] 2015 Mar-Apr [cited 2014 Dec 18];19(2):125-31. Available from: URL:http:// www.ncbi.nlm.nih. gov/pubmed/25529365.

29. Nwanko EK, Kwaru A, Ofulu A and Babashani M. 2007. Haematological changes in tuberculosis in Kano, Nigeria. J. Med. Lab. Sci., 14:35-39.

30. Morris CW, Bird AR, Nell H. 1989. The haematological and biochemical changes in severe pulmonary tuberculosis. Q.J. Med., 73: 1151-1159. 